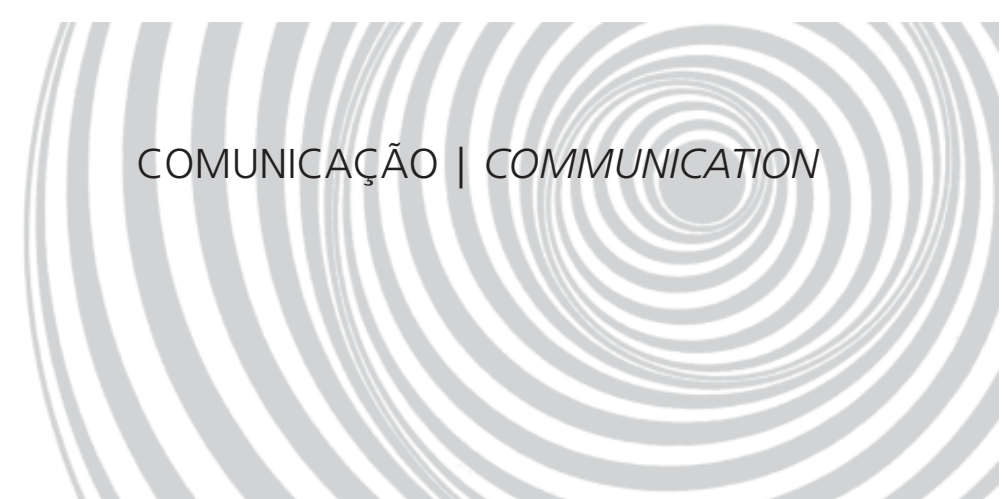

\title{
Ácidos graxos poliinsaturados ômega-3 e ômega-6: importância e ocorrência em alimentos
}

\author{
Omega-3 and omega-6 polyunsaturated fatty \\ acids: importance and occurrence in foods
}

\author{
Clayton Antunes MARTIN' \\ Vanessa Vivian de ALMEIDA ${ }^{1}$ \\ Marcos Roberto RUIZ1 \\ Jeane Eliete Laguila VISENTAINER² \\ Makoto MATSHUSHITA' \\ Nilson Evelázio de SOUZA ${ }^{1}$ \\ Jesuí Vergílio VISENTAINER ${ }^{1}$
}

\section{RE S U M O}

Os ácidos graxos poliinsaturados abrangem as famílias de ácidos graxos ômega-3 e ômega-6. Os ácidos graxos de cadeia muito longa, como os ácidos araquidônico e docosaexaenóico, desempenham importantes funções no desenvolvimento e funcionamento do cérebro e da retina. Esse grupo de ácidos graxos não pode ser obtido pela síntese de novo, mas pode ser sintetizado a partir dos ácidos linoléico e alfa-linolênico presentes na dieta. Neste artigo são considerados os principais fatores que podem inibir a atividade das enzimas dessaturases envolvidas na síntese dos ácidos graxos de cadeia muito longa. São apresentadas as recomendações da razão ômega-6/ômega-3 na dieta, propostas em diversos países, sendo verificada a convergência para o intervalo de 4 a 5:1. São relacionados alimentos que podem contribuir para aumentar a ingestão do ácido alfa-linolênico e dos ácidos graxos de cadeia muito longa. A essencialidade dos ácidos graxos de cadeia muito longa é muito dependente do metabolismo do indivíduo, sendo que a razão n-6/n-3 da dieta exerce grande influência nesse sentido.

Termos de indexação: ácidos graxos poliinsaturados; ácido eicosapentaenóico; ácidos docosahexaenóicos; ácido araquidônico; ácidos graxos ômega-3; ácidos graxos ômega-6.

\section{A B S T R A C T}

Polyunsaturated fatty acids include the classes of fatty acids designated as omega-3 and omega-6. Very-long-chain polyunsaturated fatty acids as arachidonic and docosahexaenoic have important roles in the

\footnotetext{
1 Departamento de Química, Universidade Estadual de Maringá. Maringá, PR, Brasil.

2 Departamento de Análises Clínicas, Universidade Estadual de Maringá. Av. Colombo, 5790, 87020-900, Maringá, PR, Brasil.

Correspodência para/Correspondence to: J.V.VISENTAINER. E-mail: <jvvisentainer@uem.br>.
} 
development and functioning of the brain and retina. This group of fatty acids cannot be synthesized by de novo pathway, but can be formed from linoleic and alpha-linolenic acid present in diet. In this article, the main factors that can inhibit desaturase enzymes activity involved in the synthesis of MLC-PUFAs are considered. Recommendations of omega-6/omega-3 ratio in diet proposed in several countries are presented, showing a coverage range from 4 to 5:1. Foods that are sources of alpha-linolenic acid and Very-long-chain are listed. The essentiality of Very-long-chain is very dependent of individual metabolism, and omega-6/omega-3 dietary ratio has a great influence in their health effects.

Indexing terms: polyunsaturated fatty acids; eicosapentaenoic acid; docosahexaenoic acid; arachidonic acid; fatty acids, omega-3; fatty acids, omega-6.

\section{N T R O D U ÇÃ O}

Os componentes lipídicos, especialmente os ácidos graxos, estão presentes nas mais diversas formas de vida, desempenhando importantes funções na estrutura das membranas celulares e nos processos metabólicos. Em humanos, os ácidos linoléico (18:2n-6, AL) e alfa-linolênico (18:3n-3, AAL) são necessários para manter sob condições normais, as membranas celulares, as funções cerebrais e a transmissão de impulsos nervosos. Esses ácidos graxos também participam da transferência do oxigênio atmosférico para o plasma sangüíneo, da síntese da hemoglobina e da divisão celular, sendo denominados essenciais por não serem sintetizados pelo organismo a partir dos ácidos graxos provenientes da síntese de novo ${ }^{1,2}$.

Em relação ao número de insaturações, o AL e o AAL são denominados genericamente de ácidos graxos poliinsaturados (AGPI), assim como outros ácidos que apresentam duas ou mais insaturações. Em relação ao tamanho da cadeia carbônica, os AGPI que possuem 18 ou mais átomos de carbono são denominados, por alguns autores, de ácidos cadeia longa, no entanto não há consenso na literatura sobre essa denominação. Alguns autores consideram ácidos graxos de cadeia longa aqueles que apresentam cadeia com número de átomos de carbono maior que 20 átomos ${ }^{1,3}$.

Com o propósito de contribuir para o estabelecimento de uma nomenclatura que relacione as denominações e siglas do tamanho da cadeia carbônica, serão considerados ácidos graxos poliinsaturados de cadeia longa (AGPI-CL), os ácidos que apresentam número de átomos de carbono maior que 16 , conforme a terminologia geralmente adotada. Os ácidos graxos poliinsaturados com cadeia carbônica maior que 20 átomos, serão denominados ácidos graxos poliinsaturados de cadeia muita longa (AGPI-CML), tendo como base a terminologia que vem sendo empregada em artigos envolvendo o estudo dos ácidos graxos e suas relações com a nutrição humana ${ }^{4}$.

Os AGPI-CML das famílias $n-6$ e $n-3$, aqui descritos como AGPI-CML n-6 ou AGPI-CML n-3, respectivamente, têm sido alvo de inúmeros estudos nas últimas décadas, os quais esclareceram muitas das suas funções no organismo humano e as reações envolvidas na sua formação a partir dos ácidos linoléico e alfa-linolênico. Esses estudos, também têm destacado a importância da ingestão dos AGPI-CML, na fase gestacional ${ }^{5,6}$, nos primeiros meses após o nascimento ${ }^{5,7,8}$, na terceira idade ${ }^{2,9}$ e em diversas doenças ${ }^{1,2}$, principalmente degenerativas.

Este artigo tem como objetivo analisar a importância dos AGPI-CML na nutrição humana, considerando suas funções metabólicas e os fatores que podem afetar a sua obtenção a partir dos ácidos graxos AL e AAL, reconhecidamente essenciais. São apresentadas as concentrações dos AGPI-CML, AL e AAL em diversos alimentos presentes na dieta do brasileiro, sendo também considerados os valores da razão entre os ácidos graxos n-6 e n-3 que têm sido recomendados por diversos autores e órgãos de saúde.

\section{As famílias n-6 e n-3}

As famílias n-6 e n-3 abrangem ácidos graxos que apresentam insaturações separadas 
apenas por um carbono metilênico, com a primeira insaturação no sexto e terceiro carbono, respectivamente, enumerado a partir do grupo metil terminal (Figura 1). A cadeia dos ácidos graxos também é enumerada a partir da carboxila, de acordo com a designação $\Delta$ (delta), que é mais aplicada ao estudar as reações químicas que envolvem esses ácidos. Devido às diferenças fisiológicas entre as famílias n- 6 e n-3 e à simplicidade da designação $n$, passou a ser mais apropriado empregar esta designação ao estudar aspectos nutricionais envolvendo os ácidos graxos.

Os ácidos graxos das famílias n-6 e n-3 são obtidos por meio da dieta ou produzidos pelo organismo a partir dos ácidos linoléico e alfa-linolênico, pela ação de enzimas alongase e dessaturase. As alongases atuam adicionando dois átomos de carbono à parte inicial da cadeia, e as dessaturases agem oxidando dois carbonos da cadeia, originando uma dupla ligação com a configuração cis.

No reino vegetal é muito comum a síntese do ácido linoléico, ocorrendo também a sua conversão em alfa-linolênico, pela ação de enzimas que originam dupla ligação na posição $\Delta 15^{10}$. $\mathrm{Na}$ classe dos mamíferos tem sido isoladas e identificadas dessaturases capazes de introduzir duplas ligações nas posições $\Delta 5, \Delta 6$ e $\Delta 9^{11,12}$. A $\Delta 9$ dessaturase atua, predominantemente, na síntese de ácidos graxos monoinsaturados, tendo como principal substrato o ácido esteárico (18:0), que é o precursor do ácido oléico (18:1 $\Delta 9$ ). As enzimas $\Delta 5$ e $\Delta 6$ atuam na dessaturação de ácidos graxos poliinsaturados (Figura 2), apresentando maior afinidade com os substratos mais insaturados, o que resulta em uma maior probabilidade da síntese dos AGPI-CL da família n-3 ${ }^{13}$.

Essas reações ocorrem no retículo endoplasmático, predominantemente nas células hepáticas, e tem sido aceito, por muitos anos, que a etapa final da síntese dos ácidos docosahexaenóico (22:6 n-3, ADH) e docosapentaenóico (22:5 n-6, ADP) envolve a $\Delta 4$ dessaturase, que atua sobre os ácidos 22:5 n-3 e 22:4 n-6. Embora sua existência tenha sido reconhecida em algumas espécies vegetais e microorganismos ${ }^{14}$, a dificuldade em isolar e identificar essa enzima nos mamíferos induziu à busca por evidências metabólicas de outras etapas para explicar a produção do ADH (ácido docosahexaenóico) e ADP (ácido docosapentaenóico). Essas etapas envolvem ação das enzimas alongase e $\Delta 6$ dessaturase, levando à formação dos ácidos 24:6 n-3 e 24:5 n-6, que nos peroxissomos sofrem a remoção de dois átomos de carbono, denominada de $\beta$-oxidação ${ }^{11,15}$.

Em crianças com anormalidades nos peroxissomos, que resultam na síndrome de Zellweger e em suas formas variantes, a reação de $\beta$-oxidação não é efetuada, o que impede a síntese do ADH. Nessa condição, a ingestão

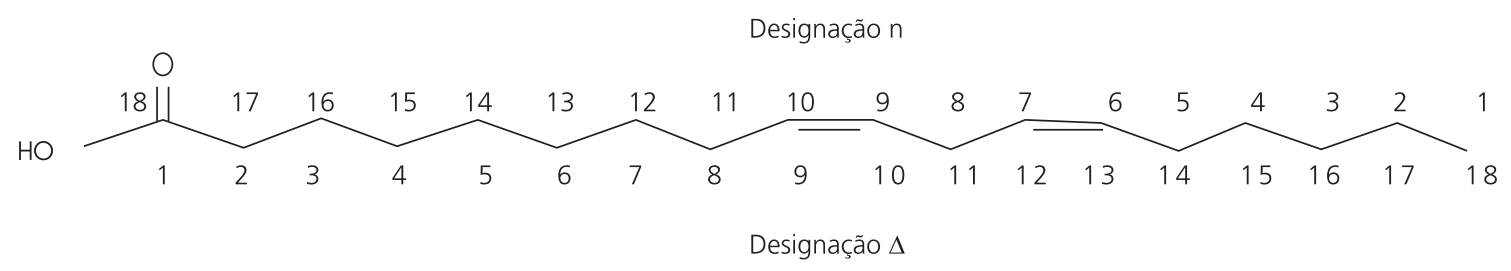

(a)

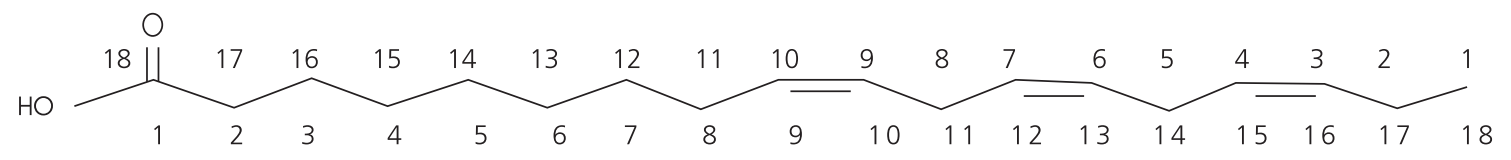

(b)

Figura 1. Estruturas dos ácidos linoléico (a) e alfa-linolênico (b). 
prolongada desse ácido graxo tem-se mostrado eficiente para amenizar os sintomas relacionados com as funções visuais, hepáticas, cerebrais e musculares ${ }^{16}$.

Estudos recentes têm sugerido que a $\Delta 6$ dessaturase, envolvida na etapa final da síntese do $A D H$ e $A D P$, corresponde à mesma enzima $\Delta 6$ empregada na dessaturação dos ácidos alfa-linolênico e linoléico ${ }^{17,18}$. Assim, os fatores que influenciam a atividade dessa enzima têm um impacto ainda maior sobre a síntese do $\mathrm{ADH} e$ ADP.

Tem sido verificado que a atividade das enzimas $\Delta 6$ e $\Delta 5$ dessaturase é diminuída por fatores como tabagismo, consumo de álcool, diabetes, estresse, ingestão elevada de gorduras trans, e, principalmente, pelo envelhecimento. $O$ estresse envolve a liberação de hormônios como as catecolaminas e os glucorticóides, que inibem fortemente a $\Delta 6$ dessaturase ${ }^{19}$. No diabetes, a baixa quantidade de insulina inibe a $\Delta 6$ e a $\Delta 5$ dessaturases, pela modulação do RNA mensageiro dessas enzimas ${ }^{12}$. Estudos realizados com animais demonstraram que os ácidos graxos trans monoinsaturados 18:1 $\Delta 3 t, 18: 1 \Delta 4 t, 18: 1 \Delta 7 t \mathrm{e}$ 18:1 $\Delta 15 t$ exercem uma forte inibição sobre a atividade da $\Delta 6$ dessaturase, sendo que os isômeros 18:1 $\Delta 3 t$ 18:1 $\Delta 9 t$, 18: $1 \Delta$ 13te 18:1 $\Delta 15 t$ são mais eficientes em inibir a $\Delta 5$ desaturase $^{20}$. Considerando que as gorduras parcialmente hidrogenadas apresentam quantidades significativas dos isômeros 18:1 $\Delta 9$ t e 18:1 $\Delta 13 t$, a ingestão elevada dessas gorduras poderá resultar em uma importante diminuição da atividade da enzima $\Delta 5^{21}$ dessaturase.

Além desses fatores, tem-se observado que a ingestão insuficiente de energia, proteínas, zinco, magnésio, cobre e das vitaminas $\mathrm{B}_{3}, \mathrm{~B}_{6} \mathrm{e}$ $C$, contribui para limitar a conversão dos ácidos AL e ALA em AGPI-CML22,23.

Em recém-nascidos tem sido verificado que as enzimas $\Delta 5$ e $\Delta 6$ dessaturases estão ativas, e mesmo bebês prematuros são capazes de produzir o ácido araquidônico (20:4 n-6, AA) e o $\mathrm{ADH}^{24}$. Contudo, inúmeros estudos têm mostrado que o leite humano apresenta os níveis mais elevados de AA e ADH nas primeiras semanas após o parto, diminuindo a uma taxa que depende da presença desses ácidos graxos na dieta materna ${ }^{25}$. Essa condição sugere que a quantidade de AA e ADH produzida pelo recém-nascido ainda é insuficiente, sendo necessária a sua ingestão.

\section{Importância dos ácidos graxos de cadeia muito longa (AGPI-CML)}

O ADH (22:6n-3) tem importante função na formação, desenvolvimento e funcionamento do cérebro e da retina, sendo predominante na maioria das membranas celulares desses órgãos. Na retina, encontra-se ligado aos fosfolipídios que estão associados à rodopsina, uma proteína que interage no processo de absorção da luz. Seu mecanismo de ação possivelmente está relacionado com o aumento na eficiência do processo de transdução da luz e com a regeneração da rodopsina. A diminuição dos níveis desse ácido graxo nos tecidos da retina tem sido associada, em recém-nascidos, com anormalidades no desenvolvimento do sistema visual, e em adultos, com a diminuição da acuidade visual26,27.

Por ser altamente insaturado, o ADH atua influenciando as propriedades físicas das membranas cerebrais, as características dos seus receptores, as interações celulares e a atividade enzimática² ${ }^{2}$ Com o envelhecimento do indivíduo, há um aumento do estresse oxidativo, que atua reduzindo os níveis do ADH e do AA no cérebro. Esse processo resulta em um aumento na proporção de colesterol no cérebro e ocorre em maior intensidade nas doenças de Alzheimer, Parkinson e na esclerose lateral amiotrófica ${ }^{28}$.

Em estudos efetuados com animais, observou-se que dietas deficientes em ácidos graxos n-3 provocam o declínio da concentração de ADH nos tecidos do cérebro e da retina, elevando a quantidade de ADP. Esses resultados evidenciam que um alto grau de insaturação é requerido no cérebro, pois, na ausência do ADH e de seus precursores, ocorre a síntese do AGPI-CL mais semelhante, o ADP29,30. 
O AA está fortemente relacionado com o desenvolvimento do cérebro e da retina durante o período gestacional e os primeiros anos de vida. Embora seja encontrado no cérebro em quantidades menores que o ADH, os fosfolipídios associados aos neurônios são altamente enriquecidos com este ácido graxo, o que tem sugerido o seu envolvimento na transmissão sináptica ${ }^{1,31}$. Pela ação das fosfolipases, estimulada por neurotrasmissores e neuromoduladores, o AA é obtido na forma de ácido graxo livre. Nessa forma, o AA permanece por um curto espaço de tempo, podendo alterar a atividade dos canais iônicos e das proteínas quinases ${ }^{32}$.

Os ácidos araquidônico, di-homo-gamalinoléico (20:3 n-6, ADGL), e eicosapentaenóico (20:5 n-3, AEP) são precursores dos prostanóides das séries 1, 2 e 3 e dos leucotrienos das séries 4 , 5 e 6 , respectivamente (Figura 2). Os prostanóides são obtidos pela enzima cicloxigenase, que converte esses ácidos graxos livres em endoperóxidos cíclicos, originando as prostaglandinas $(\mathrm{PG})$ e tromboxanos (TXA). Os leucotrienos (LT) são obtidos pela ação da enzima lipoxigenase, que também está relacionada com a produção das lipoxinas ${ }^{1,9}$

Tanto os prostanóides como os leucotrienos agem de forma autócrina e parácrina, influenciando inúmeras funções celulares que controlam mecanismos fisiológicos e patológicos no organismo ${ }^{33}$. Entre os prostanóides, a maior afinidade do AA pela ciclo-oxigenase resulta em uma maior probabilidade de obtenção das prostaglandinas e tromboxanos da série 2 . A essa série pertencem o tromboxano $A_{2}$ e as prostaglandinas $E_{2}$ e $I_{2}$, que participam de inúmeros processos inflamatórios no organismo. Contudo, os seus correspondentes da série n-3 possuem

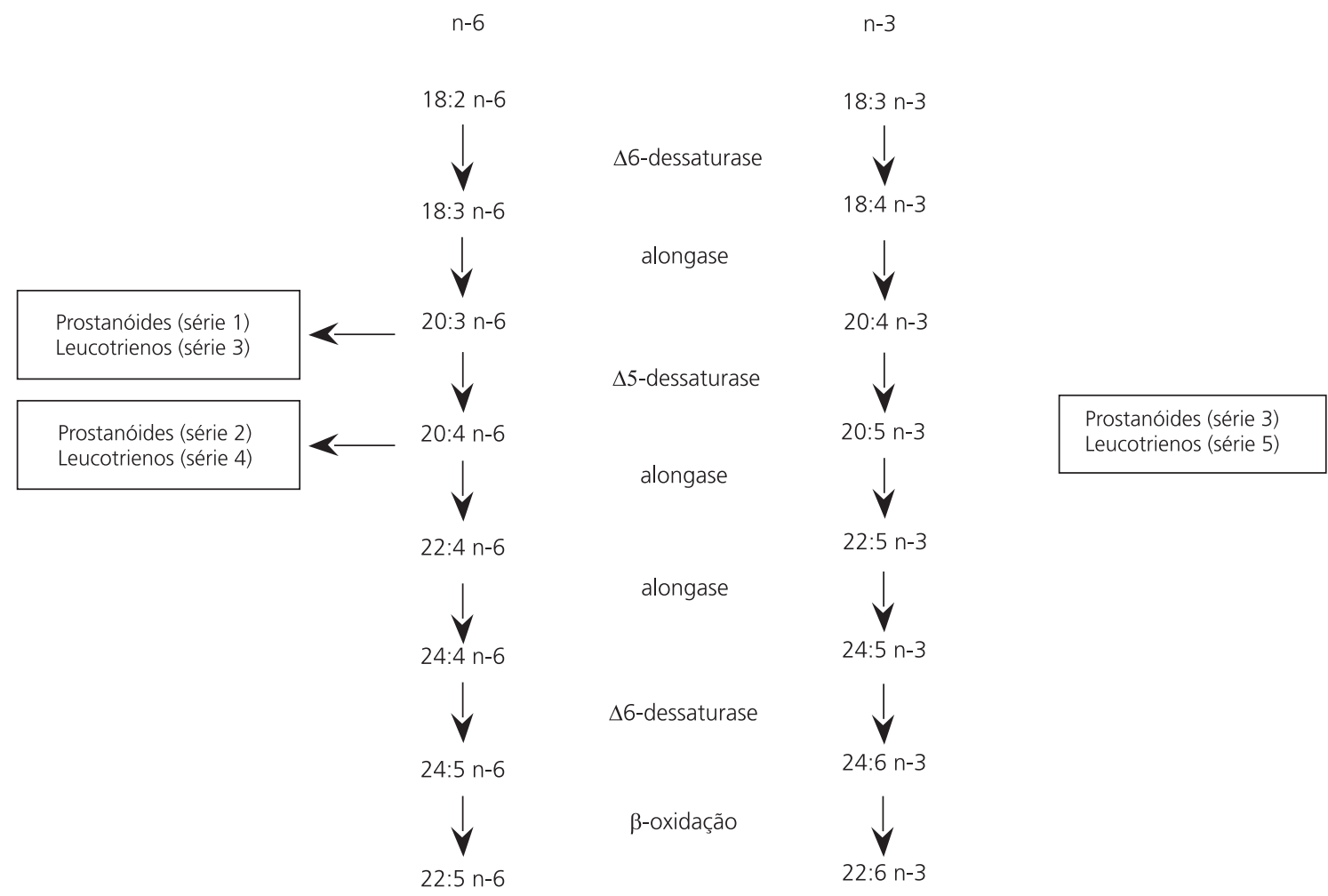

Figura 2. Metabolismo dos ácidos graxos das famílias n-6 e n-3.

Fonte: Innis ${ }^{3}$. 
propriedades anti-inflamatórias. Em função dessas diferenças fisiológicas tem-se proposto que a produção excessiva de prostanóides da série 2 está relacionada com a ocorrência de desordens imunológicas, doenças cardiovasculares e inflamatórias, sendo recomendado aumentar a ingestão de ácidos graxos n-3 para elevar a produção de prostanóides da série $3^{34}$.

\section{A razão entre os ácidos graxos n-6 e n-3}

Os ácidos graxos das famílias $n-6$ e n-3 competem pelas enzimas envolvidas nas reações de dessaturação e alongamento da cadeia. Embora essas enzimas tenham maior afinidade pelos ácidos da família n-3, a conversão do ácido alfa-linolênico em AGPI-CL é fortemente influenciada pelos níveis de ácido linoléico na dieta ${ }^{35}$. Assim, a razão entre a ingestão diária de alimentos fontes de ácidos graxos n-6 e n-3 assume grande importância na nutrição humana, resultando em várias recomendações que têm sido estabelecidas por autores e órgãos de saúde, em diferentes países.

Os valores relacionados na Tabela 1 evidenciam a tendência de convergência da razão entre os ácidos graxos n-6 e n-3 para o intervalo de 4:1 a 5:1. As razões de 2:1 a 3:1 têm sido recomendadas por alguns autores, por possibilitar uma maior conversão do ácido alfa-linolênico em ADH, que alcança o seu valor máximo em torno de 2,3:1, conforme demonstrado por Masters ${ }^{36}$. Assim, as razões entre 2:1 e 4:1 têm maior importância para pessoas com hábitos alimentares que resultam em uma baixa ingestão de AEP e ADH. Por outro lado, dietas baseadas em razões $n-6 / n-3$ inferiores a 1:1 não são recomendadas, por inibirem a transformação do ácido linoléico em AGPI-CML.

Estudos cinéticos efetuados em humanos, que foram submetidos a dietas com razões $n-6 /$ n-3 entre 6:1 e 8:1, demonstraram que a conversão do ácido alfa-linolênico em AEP e ADH varia de $8 \%$ a $21 \%$ e de $0 \%$ a $9 \%$, respectivamente, sendo observado um nível maior de conversão nas
Tabela 1. Valores recomendados para a razão entre os ácidos graxos $n-6 *$ e $n-3 *$ na dieta.

\begin{tabular}{lcl}
\hline País ou Instituição & $\mathrm{n}-6 / \mathrm{n}-3$ & \multicolumn{1}{c}{ Referências $^{2}$} \\
\hline Canadá & $4: 1-10: 1$ & SCR $^{37}$ \\
EUA & $2: 1-3: 1$ & Simopoulos $^{38}$ \\
EUA & $4: 1$ & Schaefer $^{39}$ \\
França & $5: 1$ & Chardigny et al. $^{40}$ \\
Japão & $2: 1-4: 1$ & Kris-Etherton et al. $^{41}$ \\
Suécia & $5: 1$ & NCM $^{42}$ \\
WHO/FAO & $5: 1-10: 1$ & WHO $^{43}$ \\
\hline
\end{tabular}

$\mathrm{WHO}=$ World Health Organization; $\mathrm{FAO}=$ Food and Agriculture Organization; $\mathrm{SRC}=$ Scientific Review Committee; $\mathrm{NCM}=$ Nordic Council of Ministeers; $n-6^{*}=$ ômega $6, n-3^{*}=$ ômega 3 .

mulheres $35,44,45$. Essa diferença tem sido atribuída à possível influência do estrogênio sobre a atividade das enzimas dessaturases ${ }^{45}$.

Estima-se que a razão $n-6 / n-3$ na dieta das pessoas que viveram no período que antecedeu a industrialização, estava em torno de 1:1 a 2:1, devido ao consumo abundante de vegetais e de alimentos de origem marinha, contendo ácidos graxos n-3. Com a industrialização, ocorreu um aumento progressivo dessa razão, devido, principalmente, à produção de óleos refinados oriundos de espécies oleaginosas com alto teor de $\mathrm{AL}$ e à diminuição da ingestão de frutas e verduras, resultando em dietas com quantidades inadequadas de ácidos graxos n-3. Nas últimas décadas tem-se determinado, em diversos países, que a ingestão média de ácidos graxos resulta em relações n-6/n-3 que estão entre 10:1 a 20:1, ocorrendo registros de até 50:146,47.

A necessidade de diminuir a razão $\mathrm{n}-6 /$ n-3 nas dietas modernas também tem sido sugerida pelos resultados de alguns estudos clínicos realizados na última década. Entre esses destacam-se: a diminuição de 70\% na taxa de mortalidade em pacientes com doença cardiovascular, quando a razão ALAAL na dieta foi de 4:1; a redução nas inflamações decorrentes da artrite reumatóide, quando a razão n-6/n-3 da dieta esteve entre 3 a $4: 1$, condição que foi alcançada pela suplementação com AEP, ADH e AAL; a diminuição dos sintomas decorrentes da asma, quando a 
razão n-6/n-3 da dieta esteve ao redor de 5:1, sendo que em 10:1 os sintomas foram intensificados ${ }^{48-50}$.

\section{Ocorrência de AGPI em alimentos}

Os ácidos linoléico e alfa-linolênico estão presentes tanto em espécies vegetais como animais empregados na alimentação humana. Nas hortaliças, o ácido alfa-linolênico é encontrado em maior quantidade em espécies com folhas de coloração verde-escura, por ser um importante componente da fração dos lipídios polares contidos nos cloroplastos ${ }^{47}$. Também ocorre em alguns cereais e leguminosas, sendo a sua concentração muito dependente da espécie e de fatores sazonais $^{41}$. No reino vegetal, os AGPI-CML são encontrados em plantas inferiores, que se desenvolvem principalmente em ambientes aquáticos marinhos ${ }^{47}$.

A Tabela 2 apresenta as concentrações dos ácidos linoléico e alfa-linolênico em alimentos de origem vegetal. Embora as hortaliças apresentem pequenas quantidades do ácido alfa-linolênico, devido ao seu baixo conteúdo lipídico, o consumo de vegetais, como o agrião, a couve, a alface, o espinafre e o brócolis, pode contribuir para elevar a sua ingestão, principalmente em dietas vege- tarianas. Entre os cereais e as leguminosas, a aveia, o arroz, o feijão, a ervilha e a soja, constituem importantes fontes desse ácido. Nos óleos vegetais, a maior concentração do ácido alfa-linolênico ocorre no óleo de linhaça, sendo que os óleos de canola e soja também apresentam concentrações significativas.

O ácido alfa-linolênico e os AGPI-CML estão presentes em alimentos de origem animal, como peixes e aves, sendo as suas quantidades muito dependentes da dieta a que esses animais foram submetidos ${ }^{46,47}$. Assim, inúmeros estudos têm sido conduzidos com o objetivo de estabelecer as quantidades mais apropriadas para a incorporação do ácido alfa-linolênico nas rações dos animais, que possibilitem o aumento da sua conversão enzimática para $\mathrm{AGPI-CML}$, resultando em maiores quantidades de AEP e ADH nos alimentos provenientes desses animais.

A Tabela 3 relaciona as quantidades de $A L, A A L, A A, A E P$ e ADH em alimentos de origem animal. Entre os peixes, os de origem marinha, como a sardinha e o salmão, geralmente apresentam quantidades maiores de AEP e ADH que os peixes oriundos de águas continentais. Isso ocorre, devido à expressiva quantidade desses ácidos graxos no fitoplâncton, que provê a sua distribuição ao longo da cadeia alimentar marinha. Nos alimen-

Tabela 2. Concentração dos ácidos linoléico, alfa-linolênico e razão n-6/n-3, em alimentos de origem vegetal51,52

\begin{tabular}{|c|c|c|c|c|c|c|c|}
\hline Hortaliças & $18: 2 \mathrm{n}-6(\mathrm{mg} / \mathrm{g})$ & $18: 3 \mathrm{n}-3(\mathrm{mg} / \mathrm{g})$ & $n-6 / n-3$ & Cereais e leguminosas & $18: 2 \mathrm{n}-6(\mathrm{mg} / \mathrm{g})$ & $18: 3$ n-3 (mg/g) & $n-6 / n-3$ \\
\hline Agrião $^{1}$ & 0,4 & 1,8 & 0,2 & Arroz $^{2}$ & 0,6 & 0,1 & 4,8 \\
\hline Alface $^{1}$ & 0,4 & 0,9 & 0,4 & Arroz ${ }^{2}$ (parboilizado) & 3,1 & 0,2 & 17,9 \\
\hline Brócolis $^{1}$ & 0,5 & 1,1 & 0,5 & Aveia $^{1}$ & 24,4 & 1,1 & 22,0 \\
\hline Beldroega ${ }^{1}$ & 0,9 & 4,1 & 0,2 & Ervilha $^{2}$ & 1,4 & 0,3 & 4,9 \\
\hline Couve $^{1}$ & 1,4 & 1,8 & 0,8 & Feijão² & 0,8 & 1,1 & 0,7 \\
\hline Couve-flor ${ }^{1}$ & 0,5 & 1,7 & 0,3 & Lentilha ${ }^{2}$ & 1,4 & 0,4 & 3,7 \\
\hline Espinafre $^{1}$ & 0,3 & 1,3 & 0,2 & Milho² & 58,6 & 1,8 & 32,5 \\
\hline Hortelã & 0,3 & 2,0 & 0,2 & Soja² & 44,6 & 6,0 & 7,5 \\
\hline Frutas & & & & Óleos & & & \\
\hline Abacate $^{1}$ & 16,7 & 1,3 & 12,5 & Canola & 203,0 & 93,0 & 2,2 \\
\hline Banana ${ }^{1}$ & 0,5 & 0,3 & 1,7 & Linhaça & 127,0 & 533,0 & 0,2 \\
\hline Mamão' & 0,1 & 0,3 & 0,3 & Milho & 523,0 & 11,6 & 45,1 \\
\hline Manga' & 0,4 & 0,1 & 4,0 & Oliva & 97,6 & 7,60 & 12,8 \\
\hline Morango ${ }^{1}$ & 1,8 & 0,7 & 2,6 & Soja & 510,0 & 68,0 & 7,5 \\
\hline
\end{tabular}

${ }^{1}$ Alimento cru; ${ }^{2}$ Alimento cozido. 
Tabela 3. Concentração dos ácidos linoléico, alfa-linolênico, araquidônico, eicosapentaenóico e docosaexaenóico em alimentos de origem animal ${ }^{50}$.

\begin{tabular}{|c|c|c|c|c|c|}
\hline Alimento & $18: 2$ n-6 (mg/g) & $18: 3$ n-3 (mg/g) & $20: 4$ n-3 (mg/g) & $20: 5$ n-3 (mg/g) & $22: 6 \mathrm{n}-3(\mathrm{mg} / \mathrm{g})$ \\
\hline Carne bovina ${ }^{1}$ & 4,1 & 0,4 & 0,5 & - & - \\
\hline Carne de frango ${ }^{1}$ & 46,5 & 2,5 & 1,6 & 0,2 & 0,2 \\
\hline Bagre $^{3}$ & 26,2 & 1,8 & 1,0 & 1,2 & 2,2 \\
\hline Carpa $^{2}$ & 6,6 & 3,5 & 2,0 & 3,1 & 1,5 \\
\hline Salmão² & 2,2 & 3,8 & 3,4 & 4,1 & 14,3 \\
\hline Sardinha ${ }^{1 a}$ & 35,4 & 5,0 & - & 4,7 & 5,1 \\
\hline Tilápia² & 2,9 & 0,5 & 3,5 & - & 1,3 \\
\hline Truta $^{2}$ & 2,2 & 2,0 & 2,4 & 2,6 & 6,7 \\
\hline Leite de vaca ${ }^{1}$ & 16,7 & 0,8 & - & - & - \\
\hline Leite de cabra ${ }^{1}$ & 10,9 & 0,4 & - & - & - \\
\hline Salsicha (bovina) ${ }^{1}$ & 5,7 & 0,5 & - & - & - \\
\hline Ovos (galinha) ${ }^{1}$ & 26,1 & 0,5 & 5,0 & - & 1,1 \\
\hline
\end{tabular}

${ }^{1}$ Alimento fresco; ${ }^{2}$ Cozido; ${ }^{3}$ Grelhado; aenlatada com óleo de soja.

tos provenientes de animais terrestres, que não foram submetidos a dietas com fontes adicionais de AAL, geralmente não se observa a presença de AEP e ADH. Contudo, alguns desses alimentos são fontes de AA.

\section{CONSIDERAÇÕ ES FINAIS}

Embora o organismo humano seja capaz de produzir ácidos graxos de cadeia muito longa (AGPI-CML), a partir dos ácidos linoléico (AL) e alfa-linolênico ( $A A L)$ a sua síntese é afetada por diversos fatores, que podem tornar a ingestão desses ácidos graxos essencial para a manutenção de uma condição saudável. A razão n-6/n-3 da dieta tem grande influência sobre a produção de AGPI-CML da família $n-3$, sendo que razões elevadas resultam na diminuição da produção do ácido eicosapentaenóico (AEP), condição que contribui para o desenvolvimento de doenças alérgicas, inflamatórias e cardiovasculares. Assim, é preciso efetuar estudos que permitam estimar a razão n-6/n-3 na dieta da população brasileira.

O crescente estudo sobre os processos metabólicos, que resultam na produção de inúmeros derivados dos AGPI-CML, ampliará a compreensão das funções desses ácidos graxos no organismo, intensificando o conceito da sua essencialidade. Nos próximos anos, certamente, estará disponível para o consumidor um número cada vez maior de alimentos contendo AGPI-CML. Para os alimentos de origem vegetal, isso poderá ser alcançado por meio de alterações genéticas em espécies oleaginosas, que resultarão na biossíntese desses ácidos graxos. Além disso, é preciso diminuir a ingestão diária de AL para possibilitar o aumento da produção de AGPI-CML n-3 no organismo, pois o excesso de AGPI-CML n- 6 aumenta a formação de prostanóides da série 2, condição, que é desfavorável ao organismo.

\section{A GRADECIMENTOS}

À Coordenação de Aperfeiçoamento de Pessoal de Ensino Superior (Capes) e ao Conselho Nacional de Desenvolvimento Científico e Tecnológico (CNPq), pelo suporte financeiro.

\section{REFERÊ N CIAS}

1. Youdim KA, Martin A, Joseph JA. Essential fatty acids and the brain: possible health implications. Int J Dev Neurosci. 2000; 18(4/5):383-99.

2. Yehuda S, Rabinovitz S, Carasso RL, Mostofsky DI. The role of polyunsaturated fatty acids in restoring the aging neuronal membrane. Neurobiol Aging. 2002; 23(5):843-53.

3. Innis SH. Perinatal biochemistry and physiology of long-chain polyunsaturated fatty acids. J Pediatr. 2003; 143(4 Suppl):S1-8. 
4. Guschina IA, Harwood JL. Lipids and lipid metabolism in eukaryotic algae. Progr Lipid Res. 2006; 45(2):160-86.

5. Hornstra G. Essential fatty acids in mothers and their neonates. Am J Clin Nutr. 2000; 71(5 Suppl):1262S-9

6. Sanders TAB. Essential fatty acid requirements of vegetarians in pregnancy, lactation and infancy. Am J Clin Nutr. 1999; 70(3 Suppl):555S-9.

7. SanGiovanni JP, Berkey CS, Dwyer JT, Colditz GA. Dietary essential fatty acids, long-chain polyunsaturated fatty acids, and visual resolution acuity in healthy fullterm infants: a systematic review. Early Hum Dev. 2000; 57(3):165-88.

8. Uauy R, Hoffman DR, Peirano P, Birch DG, Birch EE. Essential fatty acids in visual and brain development. Lipids. 2001; 36(9):885-95.

9. Albertazzi P, Coupland K. Polyunsaturated fatty acids. Is there a role in postmenopausal osteoporosis prevention. Maturitas. 2002; 42(1):322.

10. Nakamura MT, Nara TY. Structure, function and dietary regulation of delta- 6 , delta- 5 and delta- 9 desaturases. Annu Rev Nutr. 2004; 24(4):345-76.

11. Qiu X. Biosynthesis of docosahexaenoic acid (DHA, 22:6-4,7,10,13,16,19): two distinct pathways. Prostaglandins Leukot Essent Fatty Acids. 2003; 68(2):181-6.

12. Brenner RR. Hormonal modulation of delta 6 and delta 5 dessaturases: case of diabetes. Prostaglandins Leukot Essent Fatty Acids. 2003; 68(2):151-62

13. Brenner RR, Pelufo RO. Effect of saturated and unsaturated fatty acids on the desaturation in vitro of palmitic, stearic, oleic, linoleic and linolenic acids. J Biol Chem. 1966; 241(22):5213-9.

14. Qiu X, Hong HP, Mackenzie SL. Identification of a $\Delta 4$ fatty acid dessaturase from Thraustochytrium sp. involved in biosynthesis of docosahexaenoic acid by heterologous expression in Saccharomyces cerevisae and Brassica juncea. J Biol Chem. 2001; 276(34):38115-20.

15. Voss A, Reinhart M, Sankarappa S, Sprecher H. The metabolism of $7,10,13,16,19$-docosapentaenoic acid to $4,7,10,13,16,19$-docosahexaenoic acid in rat liver is independent of a 4-desaturase. J Biol Chem. 1991; 266(30):19995-20000.

16. Martinez M, Vázquez E, Silva MTG, Manzanares J, Bertran JM, Castelló F, et al. Therapeutic effects of docosahexaenoic acid ethyl ester in patients with generalized peroxissomal disorders. Am J Clin Nutr. 2000; 71(1):376S-85.

17. D'Andrea S, Guillou H, Jan S, Catheline D, Thibault $\mathrm{JN}$. The same rat delta 6 desaturase not only acts on 18 but also on 24-carbon fatty acids in very-long-chain polyunsaturated fatty acids biosynthesis. Biochem J. 2002; 364(1):49-55.

18. Williard DE, Nwankwo JO, Kaduce TL, Harmon SD. Identification of a fatty acid delta 6-dessaturase deficiency in human skin fibroblasts. J Lipid Res. 2001; 42(4):501-8.

19. Mills DE, Huang YS, Narce M, Poisson JP. Psychosocial stress catecholamines, and essential fatty acids metabolism in rats. Proc Soc Exp Biol Med. 1994; 205(1):56-61.

20. Mahfouz MM, Johnson S, Holman RT. The effect of isomeric trans-18:1 acids on the desaturation of palmitic, linoleic and eicosa-8,11,14-trienoic acids by rat liver microsomes. Lipids. 1980; 15(2):100-7.

21. Precht D, Molkentin J. Trans fatty acids: implications for health, analytical methods, incidence in edible fats and intake. Nahrung. 1995; 39(5):343-74.

22. Brenner RR. Nutritional and hormonal factors influencing desaturation of essential fatty acids. Prog Lipid Res. 1981; 20(1):41-7.

23. Horrobin DF. Loss of delta-6-desaturase activity as a key factor in aging. Med Hypotheses. 1981; 7(9):1211-20.

24. Carnielli VP, Wattimena DJ, Luijendijk IH, Boerlage A, Degenhost HJ, Sauer PJ. The very low birthweight premature infant is capable of sinthesizing arachidonic and docosahexaenoic acids from linoleic and linolenic acids. Pediatr Res. 1996; 40(1):169-74

25. Jensen RG. Lipids in human milk. Lipids. 1999; 34(12):1243-71

26. SanGiovanni JP, Chew EY. The role of omega-3 long chain polyunsaturated fatty acids in heath and disease of the retina. Progr Retin Eye Res. 2005; 24(1):87-138.

27. Chen $Y$, Hougton LA, Brenna JT, Noy N. Docosahexaenoic acid modulates the interactions of the interphotoreceptor retinoid-binding protein with 11-cis-tetinal. J Biol Chem. 1996; 271(34): 20507-15.

28. Simonian NA, Coyle JT. Oxidative stress in neurodegenerative diseases. Ann Rev Pharmacol Toxicol. 1996; 36(1):83-106.

29. Anderson GJ, Connor, WE. Accretion of n-3 fatty acids in the brain and retina of chick fed a low linolenic acid diet supplemented with docosahexaenoic acid. Am J Clin Nutr. 1994; 59(6):1338-46

30. Neuringer M, Connor WE, Lin DS, Barstad L, Luck S. Biochemical and functional effects of prenatal and postnatal omega 3 deficiency on retina and 
brain rhesus monkeys. Proc Natl Acad Sci USA. 1986; 83(11):4021-5.

31. Piomelli D. Eicosanoids in synaptic transmission. Crit Rev Neurobiol. 1994; 8(1):65-83.

32. Piomelli D. Arachidonic acid [cited 2005 Aug 5]. Available from: http://www.acnp.org/g4/ GN401000059/Default.htm

33. Smith WL. Prostanoid biosynthesis and mechanism of action. Am J Physiol Renal Physiol. 1992; 263(2 Pt 2):F181-91.

34. Simopoulos, AP. Omega-6/omega-3 essential fatty acid ratio and chronic diseases. Food Rev Int. 2004; 20(1):77-90.

35. Emken EA, Adlof RO, Gulley RM. Dietary linoleic acid influences desaturation and acylation of deuterium-labeled linoleic and linolenic acids in young adult males. Biochim Biophys Acta.1994; 1213(3):277-88

36. Masters C. n-3 Fatty acids and the peroxissome. Mol Cell Biochem. 1996; 165(2):83-93.

37. Scientific Review Committee. Nutrition recommendations. Ottawa: Canadian Government Publishing Centre, Supply and Services Canada; 1990.

38. Simopoulos AP, Leaf A, Salem N. Essentiality and recommended dietary intakes for omega- 6 and omega-3 fatty acids. Ann Nutr Metabol. 1999; 43(3):127-30.

39. Schaefer EJ. Lipoproteins, nutrition, and heart disease. Am J Clin Nutr. 2002; 75(2):191-212.

40. Chardigny JM, Bretillon L, Sébédio JL. New insights in health effects of trans alpha-linolenic acid isomers in humans. Eur J Lipid Sci Technol. 2001; 103(7):478-82

41. Kris-Etherton PM, Taylor DS, Yu-Poth S, Huth P, Moriarty K, Fishell $V$, et al. Polyunsaturated fatty acids in the food chain in the United States. Am J Clin Nutr. 2000; 71(1 Suppl):179S-88.

42. Nordic Council of Ministers. Nordic nutrition recommendations. Scand J Nutr. 1996; 40(4): 161-5.
43. World Health Organization. Joint Consultation: fats and oils in human nutrition. Nutr Rev. 1995; 53(7):202-5.

44. Burdge GC, Wootton SA. Conversion of alpha-linolenic acid to eicosapentaenoic, docosapentaenoic and docosahexaenoic acids in young women. Br J Nutr. 2002; 88(4):411-20.

45. Burdge GC, Jones AE, Wootton SA. Eicosapentaenoic and docosapentaenoic acids are the principal products of alpha-linolenic acid metabolism in young men. Br J Nutr. 2002; 88(4):355-63.

46. Simopoulos AP. Omega-6/Omega-3 essential fatty acid ratio and chronic diseases. Food Rev Inter. 2004; 20(1):77-90.

47. Simopoulos AP. Omega-3 fatty acids in wild plants, nuts and seeds. Asia Pacific J Clin Nutr. 2002; 11(6):S163-73.

48. Lorgeril M, Renaud S, Mamelle N, Salen P, Martin $J$, Monjaud I, et al. Mediterranean alpha-linolenic acid rich diet in secondary prevention of coronary heart disease. Lancet. 1994; 343(8911):1454-9

49. James ML, Cleland LG. Dietary n-3 fatty acids and therapy for rheumatoid arthritis. Semin Arthritis Rheum. 1997; 27(2):85-97.

50. Broughton KS, Johnson CS, Pace BK, Liebman M, Kleppinger KM. Reduced asthma symptoms with n-3 fatty acid ingestion are related to 5-series leukotriene production. Am J Clin Nutr. 1997; 65(4):1011-7.

51. Pereira C, Li D, Sinclair AJ. The alpha-linolenic acid content of green vegetables commonly available in Australia. Int J Vitam Nutr Res. 2001; 71(4): 223-8.

52. United States Department of Agriculture, National Agriculture Library. Food and Nutrition Data Laboratory [cited 2006 Mar 30]. Available from: http://www.nal.usda.gov/fnic/foodcomp/search/

Recebido em: 25/8/2005

Versão final reapresentada em: 21/8/2006 Aprovado em: 31/8/2006 